OPEN ACCESS

Edited by:

Maria Cristina Dantas Vanetti, Universidade Federal de Viçosa, Brazil

Reviewed by:

Antonio Valero,

University of Córdoba, Spain Christian Scarano,

Università degli Studi di Sassari, Italy

*Correspondence:

Valentina Bernini

valentina.bernini@unipr.it

Specialty section:

This article was submitted to

Food Microbiology,

a section of the journal

Frontiers in Microbiology

Received: 10 July 2020

Accepted: 07 December 2020

Published: 06 January 2021

Citation:

Ricci A, Alinovi M, Martelli F Bernini V, Garofalo A, Perna G, Neviani $E$ and Mucchetti G (2021)

Heat Resistance of Listeria monocytogenes in Dairy Matrices Involved in Mozzarella di Bufala

Campana PDO Cheese.

Front. Microbiol. 11:581934. doi: 10.3389/fmicb.2020.581934

\section{Heat Resistance of Listeria monocytogenes in Dairy Matrices Involved in Mozzarella di Bufala Campana PDO Cheese}

\author{
Annalisa Ricci ${ }^{1}$, Marcello Alinovi ${ }^{1}$, Francesco Martelli ${ }^{1}$, Valentina Bernini ${ }^{1 *}$, \\ Alessandro Garofalo ${ }^{2}$, Giampiero Perna ${ }^{2}$, Erasmo Neviani ${ }^{1}$ and Germano Mucchetti ${ }^{1}$ \\ ${ }^{1}$ Department of Food and Drug, University of Parma, Parma, Italy, ${ }^{2}$ Research and Development, Consorzio Tutela \\ Mozzarella di Bufala Campana DOP, Caserta, Italy
}

The presence of Listeria monocytogenes in Mozzarella di Bufala Campana Protected Designation of Origin cheeses may depend on curd stretching conditions and post contaminations before packaging. To avoid cross-contamination, thermal treatment of water, brines and covering liquid may become necessary. The present study aimed to improve knowledge about $L$. monocytogenes thermal resistance focusing on the influence of some cheese making operations, namely curd stretching and heat treatment of fluids in contact with cheese after molding, in order to improve the safety of the cheese, optimize efficacy and sustainability of the processes. Moreover, the role that cheese curd stretching plays in L. monocytogenes inactivation was discussed. The 12 tested strains showed a very heterogeneous heat resistance that ranged from 7 to less than $1 \log _{10} \mathrm{Cfu} / \mathrm{mL}$ reduction after $8 \mathrm{~min}$ at $60^{\circ} \mathrm{C}$. $D$-values (decimal reduction times) and $z$-values (thermal resistance constant) calculated for the most heat resistant strain among 60 and $70^{\circ} \mathrm{C}$ were highly affected by the matrix and, in particular, heat resistance noticeably increased in drained cheese curd. As cheese curd stretching is not an isothermal process, to simulate the overall lethal effect of an industrial process a secondary model was built. The lethal effect of the process was estimated around $4 \log _{10}$ reductions. The data provided may be useful for fresh pasta filata cheese producers in determining appropriate processing durations and temperatures for producing safe cheeses.

Keywords: food safety, L. monocytogenes, thermal resistance, dairy matrices, stretching, $D$-value, z-value

\section{INTRODUCTION}

Fresh pasta filata cheeses have been usually considered among the microbiologically safe cheeses because of the supplementary effect of the stretching of the acid cheese curd with hot or boiling water. Nonetheless, Mozzarella di Bufala Campana (MBC) Protected Designation of Origin (PDO) cheese is characterized by $\mathrm{pH}(>5.1)$ and water activity $\left(\mathrm{a}_{w}>0.975\right)$ values that do not allow to automatically consider it as food not able to support Listeria monocytogenes growth, according to Commission Regulation (EC) No. 2073/2005 (2020). From 1998 to 2017 out of more than 
370 cases of cheese microbial contamination, only three cases of Mozzarella withdrawn from the market because of the presence of L. monocytogenes have been reported by European Rapid Alert System for Food and Feed (RASFF Portal, 2020). Suddenly, in 2018 and 2019 three recalls of MBC occurred in France (RASFF 2018/1198 and 2018/2459) and in Canada (Canadian Food Inspection Agency (CFIA), 2019), because of the presence of L. monocytogenes. This unusual contamination has urgently raised the need to investigate on its possible reasons, since the risk profile of MBC may be considered lower than the more widely consumed cow milk Mozzarella, because of the higher acidity of the cheese curd ( $\mathrm{pH} 4.8$ vs $\mathrm{pH}$ 5.1) and the higher temperature of the stretched curd at the end of the process (about 68$72^{\circ} \mathrm{C}$ vs $58-63^{\circ} \mathrm{C}$; Mucchetti and Neviani, 2006). The stretching process of buffalo cheese curd is associated to significant but extremely variable decimal reductions of $L$. monocytogenes count, ranging from 1 to 8 , as resulted by some studies performed with laboratory scale cheese making trials (Villani et al., 1996; Raimundo et al., 2013; Serraino et al., 2013; Murru et al., 2018). The survival probability depends on the cheese curd contamination, the effective conditions of stretching applied during the experiments, often not fully described, and the heat resistance of biotypes. Up to present, at the best of our knowledge, no L. monocytogenes contamination has been reported in MBC cheese curds. Its presence at the moment of stretching is believed to be occasional and lower than the counts measured during challenge tests, where artificial curd contamination ranged from $10^{3}$ to $10^{7} \mathrm{CFU} / \mathrm{g}$. In these challenge tests, L. monocytogens was added to milk, and during cheese curd maturing a decrease (Murru et al., 2018) or even a small but significant growth (Serraino et al., 2013) have been observed. The degree of L. monocytogenes survival after stretching may be associated to the stretching conditions, as the overall amount of thermal and mechanical energy applied, that determine the temperature and time of permanence of the cheese curd at lethal temperature, is inversely related to the degree of cheese curd maturity and demineralization. Indeed, to obtain a cheese with the standard and typical MBC structure, the cheesemaker lowers the stretching temperature when the cheese curd has a too low $\mathrm{pH}$ and, as a consequence, an excessive extent of casein demineralization (Mucchetti and Neviani, 2006; Mucchetti et al., 2016).

Moreover, further aspects should be considered to explain the variable effects of curd stretching on L. monocytogenes survival. First, heterogeneity (genetic or phenotypic diversity) within a population, can promote adaptation and survival when the population experiences sudden environmental changes (Ryall et al., 2012; Davis and Isberg, 2016). These phenomena may explain the ability of a fraction of a bacterial population to withstand stresses that kill the majority of the population itself (Booth, 2002), and could be associated both to Listeria spp. biodiversity (Bernini et al., 2013) and to the presence of isogenic variants, able to influence its heat tolerance, e.g., because of a different ability to repair cell membrane after sub lethal heat injury (Somolinos et al., 2010). Heterogeneity can further contribute to explain the limits of the widely used primary model of Bigelow (Bigelow, 1921), when deviations from linear relationship between time of heat treatment and survival are observed (Cebrian et al., 2017). The heat resistance range of L. monocytogenes biotypes is quite variable, as reported by Doyle et al. (2001) and Aryani et al. (2015b), with $D$-values at $60^{\circ} \mathrm{C}$ ranging from few seconds to more than $4 \mathrm{~min}$, and decreases at low $\mathrm{pH}$, high $\mathrm{a}_{w}$ and low $\mathrm{NaCl}$ content (Jørgensen et al., 1995; Mazzotta, 2001; Bucur et al., 2018). Heat resistance of L. monocytogenes is also influenced by the growth phase, with the cells in exponential phase being more heat sensitive than those in stationary phase (Lou and Yousef, 1996; Jørgensen et al., 1999; Aryani et al., 2015b), and by stress adaptation phenomena, e.g., acid and or osmotic stress (Jørgensen et al., 1995; De Jesús and Whiting, 2003). Moreover, it may be interesting to note that some $D$ - and $z$-values measured in some complex food matrices (meat, eggs) were significantly higher than those determined in culture media as Tryptone Soy Broth (TSB; Quintavalla and Campanini, 1991; Doyle et al., 2001), confirming the role of the interaction of microorganisms with the matrix in determining its stress tolerance.

Furthermore, the presence of L. monocytogenes in MBC can also be the result of post-contamination during the processing steps after stretching and before packaging. After stretching, MBC cheese is hardened and cooled by dipping into flowing tap water, salted by immersion in a brine and finally packed by dipping into a covering liquid, composed by salt and organic acids (e.g., lactic acid; Mucchetti and Neviani, 2006). Potentially, the contamination of these fluids can be transferred to the cheese, but at present time no data demonstrated the presence of $L$. monocytogenes in tap water and/or brines and/or covering liquids used for MBC cheese making. However, even if the presence of L. monocytogenes in tap water is not largely documented (Lyautey et al., 2007), its ability to survive (Budzińska et al., 2012), and to create biofilm (Gião and Keevil, 2014) has been determined. Otherwise, the presence of $L$. monocytogenes in brines of different cheeses has been detected using analytical tools as quantitative polymerase chain reaction (PCR) (Alessandria et al., 2010; Barancelli et al., 2014), and its ability to survive was inversely related to the acidity and $\mathrm{NaCl}$ content of the brine itself (Schirmer et al., 2014). The presence of this pathogen on cheese surface and/or on equipment may result in water and brine contamination, causing the beginning of a non-controlled cross-contamination. Also, the more frequent presence of Listeria spp. on nonfood contact surfaces (floor, drains, walls, and platforms) may become a potential route of cheese contamination (Barancelli et al., 2014). To avoid cheese cross-contamination, the treatment of water, brines and covering liquid may become necessary. Beside heat processes, filtration, and/or UV-C treatment (Gayan et al., 2015) can be effective in reducing the count of L. monocytogenes. However, heat treatments can lead to more reproducible results.

Knowledge of decimal reduction time ( $D$-value) and thermal resistance constant ( $z$-value) in each out of these matrices can allow to build primary and secondary models able to foresee the lethal effect of heat treatments, contributing to improve the efficacy and the sustainability of the processes, avoiding to waste energy and/or time, mainly when batch treatments are applied as occur in many small sized MBC dairies. The $D$-value is the time 
required to obtain a ten-fold reduction of a microbial population at a constant lethal temperature and it varies according to the microorganism and to the medium where heat is applied. The $z$-value is the temperature variation required for the $D$-value to change by a factor of ten. Using these parameters, it is possible to foresee the effect of a thermal treatment, accepting that the death rate follows a first order reaction kinetics. Despite the death rate of many microorganisms does not always or completely follow this order of kinetics, suggesting that other models (e.g., Weibull frequency distribution models or non-loglinear Geeraerd's model) could be applied (Peleg and Cole, 1998; Mafart et al., 2002; Geeraerd et al., 2005; Cebrian et al., 2017), the linear model (Bigelow, 1921) continues to offer a relevant contribution to predict the effect of a heat treatment. However, in the presence of a non-isothermal temperature profile, as in the case of curd stretching operation, it is necessary to develop a secondary model able to simulate the overall lethal effect of the treatment.

The aims of this study were (i) the selection of the most heat resistant L. monocytogenes among a pool of dairy origin strains, (ii) the estimation of $D$ and $z$ values of this strain using as matrices MBC cheese curd and the fluids coming into contact with MBC cheese after cheese molding, such as hardening water, brine and fresh covering liquid; (iii) the proposal of a secondary model able to estimate the cumulative effect of the stretching process on L. monocytogenes survival. Following this approach, we aimed to improve the knowledge about the influence of the matrix on heat resistance and to better understand the role that cheese curd stretching plays in L. monocytogenes inactivation.

\section{MATERIALS AND METHODS}

\section{Culture Preparation}

Twelve L. monocytogenes strains were overall considered in this study. Among these, ten strains (Lm1, Lm2, Lm3, Lm4, Lm5, Lm8, Lm15, Lm16, Lm21, and Lm28) isolated from Gorgonzola cheese (Bernini et al., 2013) and belonging to the collection of Food and Drug Department of the University of Parma, and two reference strains (Lmg 21263 corresponding to Atcc 13932, isolated from a clinical patient affected by meningitis, and Lmg 13305 corresponding to Dsm 15675, isolated from soft cheese) purchased from $\mathrm{Bccm}$ (Belgian Co-ordinated Collections of Microorganisms) of Ghent University, Belgium were considered. The stock cultures were kept frozen at $-80^{\circ} \mathrm{C}$ in Tsb (Vwr, Milano, Italy) added with $12.5 \%$ glycerol $(\mathrm{v} / \mathrm{v})$. They were recovered in TSB (VWR) enriched with $0.6 \%$ yeast extract (Oxoid, Basingstoke, United Kingdom) and incubated at $37^{\circ} \mathrm{C}$ overnight. The procedure was replicated three times. The counts after overnight growth were determined in Agar Listeria according to Ottaviani and Agosti (ALOA; VWR, Milano, Italy) incubated at $37^{\circ} \mathrm{C}$ for $48 \mathrm{~h}$. Before being used for heat resistance experiments, microbial cells were separated by centrifugation (Centrifuge $5810 \mathrm{R}$, Eppendorf) at $12,857 \mathrm{~g}$ for $5 \mathrm{~min}$ at $25^{\circ} \mathrm{C}$, washed twice in Ringer solution (Oxoid, Milan, Italy) and finally resuspended in Ringer solution to reach the proper cell concentration.

\section{Thermal Resistance Screening of L. monocytogenes Strains in vitro Conditions}

The selection of the strain with the highest heat resistance was carried out as follows. Small volumes of Tsb (Vwr; $2.970 \mathrm{~mL}$ ) were pre-heated in conical plastic tubes $(50 \mathrm{~mL}$ capacity) in a water bath (Type M900-Ti Basic, Instruments s.r.l, Italy) until they reached the temperature of $60^{\circ} \mathrm{C}$. Then $0.03 \mathrm{~mL}$ of each strain was inoculated in different pre-heated Tsb aliquots in order to obtain a final concentration ranged from 6 to $7 \log _{10}$ $\mathrm{Cfu} / \mathrm{mL}$. The inoculated solutions were rapidly mixed and kept for $8 \mathrm{~min}$ at $60^{\circ} \mathrm{C}$. In order to obtain a rapid temperature decrease and stop the heat treatment the suspensions were chilled by immersion into a water bath with melting ice to fulfill the condition of iso-temperature, monitoring the temperature with type- $\mathrm{K}$ thermocouples. The initial and the residual microbial concentration were checked on ALOA (Vwr) at $37^{\circ} \mathrm{C}$ for $48 \mathrm{~h}$. The detection limit was $1 \log _{10} \mathrm{Cfu} / \mathrm{mL}$ and the tests were performed in duplicate.

\section{Determination of L. monocytogenes Heat Resistance in TSB, Hardening Water, Brine, Covering Liquid, and Cheese Curd}

The strain that showed the highest heat resistance was selected and further tested to estimate $D$ and $z$ values in the range from 60 to $70^{\circ} \mathrm{C}$ in TSB and in different matrices of MBC cheese production chain: hardening water, brine, covering liquid, and cheese curd. Matrices were provided by Consorzio Tutela MBC DOP, with these main characteristics:

(i) hardening water represents a sample of pasteurized tap water that was used to chill $\mathrm{MBC}$ in a continuous equipment without recycle of the water;

(ii) brine is a freshly prepared light brine $(\mathrm{NaCl}$ concentration $4 \mathrm{~g} / 100 \mathrm{~g}$, titratable acidity $6^{\circ}$ Soxhlet-Henkel Sh/50 mL) used to salt $\mathrm{MBC}$ according to the rules of MBC production standard;

(iii) covering liquid is a pasteurized solution of $0.05 \mathrm{~g} / 100 \mathrm{~mL}$ of lactic acid (titratable acidity $6^{\circ} \mathrm{Sh} / 50 \mathrm{~mL}$; $\mathrm{pH} 2.9$ );

(iv) cheese curd is mature MBC cheese curd (about $45 \%$ of moisture content, $\mathrm{a}_{w}$ 0.99) sampled before the stretching step and immediately frozen at $-18^{\circ} \mathrm{C}$.

A small volume $(0.985 \mathrm{~mL})$ of each fluid matrix was warmed at the selected temperature immerging conical plastic tubes $(50 \mathrm{~mL}$ capacity) into a water bath (Type M900-Ti Basic, Instruments s.r.l, Italy) to reach the target equilibrium temperature. Then $0.015 \mathrm{~mL}$ of $L$. monocytogenes washed cell suspension was added; the inoculated fluid matrix was then rapidly mixed and kept for the scheduled time at the set temperature (that ranged from 60 to $\left.70^{\circ} \mathrm{C}\right)$. The suspensions $(1 \mathrm{~mL})$ were chilled by dilution into $9 \mathrm{~mL}$ of Ringer solution (Oxoid) at $4^{\circ} \mathrm{C}$. In this way, as checked by temperature monitoring with type-K thermocouples, the conditions of iso-temperature were fulfilled. The initial and 
residual counts were made on Aloa (Vwr) at $37^{\circ} \mathrm{C}$ for $48 \mathrm{~h}$. The detection limit was $1 \log _{10} \mathrm{Cfu} / \mathrm{mL}$.

The test in $\mathrm{MBC}$ cheese curd was performed introducing a step of preparation of the matrix, as its warming determines a whey syneresis. So, $10 \mathrm{~g}$ of cheese curd were poured into a conical plastic tube (50 $\mathrm{mL}$ capacity) and kept into a water bath at the set temperature $\left(62\right.$ to $\left.70^{\circ} \mathrm{C}\right)$ up to $30 \mathrm{~min}$ for completing the whey separation. Total solids and $\mathrm{a}_{w}$ of the drained cheese curd were measured according to Idf standard 4A (1982) and by AquaLab Water Activity Meter Series 3TE with internal temperature control (Decagon Devices, Inc., Pullman, WA, United States), respectively. Then $1.97 \mathrm{~g}$ of drained cheese curd was poured into a new conical plastic tube and, when equilibrated at the target temperature of treatment, $0.03 \mathrm{~mL}$ of $L$. monocytogenes washed cell suspension was inoculated directly into the hot mass and kept for the scheduled times. After treatment, instantaneous chilling to nonlethal temperature was obtained by the addition of $18 \mathrm{~mL}$ of Ringer solution (Oxoid) at $4^{\circ} \mathrm{C}$. All the trials were performed in duplicate.

\section{Estimation of $D$ - and $z$-Values for the Primary Model}

The $D$-value, that is the absolute value of the inverse slope of the linear regression line between the $\log _{10}$ of surviving cells number and time (s), was calculated considering at least three out of four or more measures performed at different times for each experiment and falling into the linear portion of the regression line. The absolute value of the inverse slope of the linear regression line between the average $\log _{10} D$-values and temperature was the $z$-value.

\section{Simulation of the Effect of Cheese Curd Stretching on $L$. monocytogenes Survival}

In order to benchmark the results of L. monocytogenes thermal inactivation obtained in cheese curd, an exemplificative Mbc curd stretching process was considered according with temperature data obtained from observations made in Mbc dairies (Table 3). The process was divided into four key steps: melting caused by curd mixing with hot water, kneading of melted curd, cheese molding, and cooling (Table 3). To estimate the effect of cheese curd stretching step on L. monocytogenes survival, a secondary model was built applying the following procedure:

(i) Estimation of $D$-values at all the lethal temperatures (Tx) involved in the process on the basis of Eq. 1, using a primary linear model, with $\mathrm{T}_{R E F}=70,0^{\circ} \mathrm{C}$;

$$
D_{T_{X}}=D_{T_{\mathrm{REF}}} 10^{-\frac{T_{X}-T_{\mathrm{REF}}}{z}}
$$

(ii) calculation of the estimated time of permanence of the coldest spot of the cheese curd at lethal temperature (e.g., from 60 to $70^{\circ} \mathrm{C}$ ) both during the stretching operation and the initial step of cooling; (iii) the time of permanence at each temperature was divided by the corresponding $D$-values to obtain the $\log _{10}$ count reduction at each temperature;

(iv) finally, the sum of the lethal effects at each temperature represents the overall lethal effect given by the process.

\section{RESULTS}

\section{Selection of the Most Heat Resistant L. monocytogenes Strain}

In general, the heat resistance of the 12 strains was heterogeneous. Among all the tested strains, Lm15 was the most heat resistant showing a decrease in cell concentration of less than $1 \log _{10}$ $\mathrm{CFU} / \mathrm{mL}$ after $8 \mathrm{~min}$ of heating at $60^{\circ} \mathrm{C}$ in TSB. L. monocytogenes LMG 21264, isolated from a patient affected by meningitis, was the most heat sensitive strain; L. monocytogenes $\operatorname{Lm} 3, \operatorname{Lm} 8, \operatorname{Lm} 21$, Lm28, and LMG 13305 were the most sensitive among the strains isolated from cheese (Table 1).

\section{Estimation of $D$ - and $z$-Values of L. monocytogenes Lm15 Strain in Dairy Matrices}

$D$-values of Lm15 estimated at temperatures ranging from 60 to $70^{\circ} \mathrm{C}$ in fluid media and between 62 and $70^{\circ} \mathrm{C}$ in drained cheese curd have been strongly affected by the matrix (Table 2). Considering the fluid matrices, the high presence of organic matter in TSB $(31.5 \mathrm{~g} / \mathrm{L})$ appeared to protect the cells from heat damage at all three temperatures considered. The acidic $\mathrm{pH}$ (2.9) of covering liquid that was due to the presence of lactic acid contributed to negatively affect the heat resistance of Lm15; on the contrary, this strain showed a higher thermal resistance in the hardening water and in the brine. Heat resistance of Lm15 increased noticeably at all the tested temperatures when measured in the drained cheese curd, characterized by a total solid content of $63.4 \%$ and $\mathrm{a}_{w}$ value of 0.989 , because of

TABLE 1 | $\log _{10}$ reduction of $L$. monocytogenes tested strains after $8 \mathrm{~min}$ at $60^{\circ} \mathrm{C}$ in in vitro conditions.

\begin{tabular}{lcccc}
\hline Strain & \multicolumn{3}{c}{ Log $_{10} \mathbf{C F U} / \mathbf{m L}$} \\
\cline { 2 - 5 } & Trial A & Trial B & Mean & SD \\
\hline Lm1 & 1.86 & 1.56 & 1.71 & 0.21 \\
Lm2 & 1.12 & 1.83 & 1.48 & 0.50 \\
Lm3 & 5.28 & 5.31 & 5.29 & 0.03 \\
Lm4 & 3.50 & 4.38 & 3.94 & 0.62 \\
Lm5 & 3.21 & 2.76 & 2.98 & 0.32 \\
Lm8 & 4.98 & 5.34 & 5.16 & 0.25 \\
Lm15 & 0.52 & 0.72 & 0.62 & 0.14 \\
Lm16 & 2.92 & 2.61 & 2.76 & 0.22 \\
Lm21 & 4.55 & 6.20 & 5.37 & 1.17 \\
Lm28 & 6.72 & 6.37 & 6.55 & 0.25 \\
LMG 21264 & 7.08 & 7.04 & 7.06 & 0.03 \\
LMG 13305 & 4.90 & 5.70 & 5.30 & 0.56
\end{tabular}


TABLE $2 \mid D$-values and $z$-values of $L$. monocytogenes $L m 15$ in different matrices.

\begin{tabular}{lcccc}
\hline Matrix & $\mathbf{p H}$ & Temperature $\left({ }^{\circ} \mathbf{C}\right)$ & $\boldsymbol{D}$-value $(\mathbf{s})$ & $\mathbf{z}$-value $\left({ }^{\circ} \mathbf{C}\right)$ \\
\hline TSB & 7.2 & $60.1 \pm 0.3$ & $284.4 \pm 17.3$ & 6.4 \\
& & $67.3 \pm 0.1$ & $19.3 \pm 2.3$ & \\
Hardening water & 7.2 & $60.2 \pm 0.6$ & $8.4 \pm 0.3$ & \\
& & $67.4 \pm 0.2$ & $90.7 \pm 5.0$ & 8.2 \\
Brine & & $70.2 \pm 0.2$ & $6.1 \pm 0.1$ & \\
& 3.2 & $60.0 \pm 0.1$ & $84.4 \pm 4.9$ & 10.1 \\
Covering liquid & & $67.5 \pm 0.2$ & $16.4 \pm 0.4$ & \\
& & $70.4 \pm 0.1$ & $7.7 \pm 0.1$ & \\
Drained cheese curd & 5.9 & $60.1 \pm 0.2$ & $22.1 \pm 0.7$ & 9.8 \\
& & $67.2 \pm 0.1$ & $4.3 \pm 0.1$ & \\
& & $70.2 \pm 0.2$ & $2.1 \pm 0.2$ & \\
& & $62.3 \pm 0.4$ & $423.5 \pm 26.6$ & 11.1 \\
& & $66.4 \pm 0.1$ & $188.9 \pm 19.4$ & \\
& & $70.0 \pm 0.3$ & $85.4 \pm 7.2$ & \\
\hline
\end{tabular}

whey separation that was caused by the preliminary equilibration step to heating temperature. Even the $z$-values were affected by the different matrices, with values much higher for the dairy matrices (about $10^{\circ} \mathrm{C}$ ) compared to the synthetic medium TSB $\left(6.4^{\circ} \mathrm{C}\right)$.

\section{Simulation of the Effect of Cheese Curd Stretching on $L$. monocytogenes Survival}

As stretching is not a fully isothermal operation, its lethal effect on Lm15 should be foreseen based on the temperature profile of the curd. On the basis of the hypothesized curve temperature vs cumulative time (Table 3), four steps of the process contributing to the overall lethal effect can be identified. The cumulative lethal effect of the first three steps, where mixing and kneading contribute to a roughly homogeneous heating rate, can be estimated around $4 \log _{10}$ reductions (3.92 $\log _{10}$ in the example) of Lm15 strain (Table 3). In the center of the MBC cheese ball, being the slowest point to be chilled, the lethal effect can increase to more than $6 \log _{10}$ count reduction. Conversely, in the external part of the cheese (which temperature decrease is not estimated in Table 3) because of the very fast cooling to sublethal temperature the count reduction does not overcome the one obtained during stretching ( $\sim 4 \log _{10}$ count reduction). To foresee the overall lethal effect of the thermal treatment, the zone where the effect is lower has to be considered. Furthermore, the outer zone of the cheese is the most subjected to post-contamination by contact with hardening water, brine, and covering liquid.

\section{DISCUSSION}

A large variability of heat resistance among the L. monocytogenes strains tested was observed in this study and it has to be taken into account in future studies on L. monocytogenes survival during heat processes of food products. Our results in TSB medium agree with previously reported data (Doyle et al., 2001; Aryani et al., 2015b). A similar high heat resistance was found by Quintavalla and Campanini (1991) for a strain isolated from meat and tested in the same matrix. Curiously, the most heat resistant strain among the 20 tested by Aryani et al. (2015b), with the majority of them of food origin, was isolated from milk. Otherwise, some strains showed a very low heat resistance; the most heat sensitive strain was a reference strain (LMG 21264, isolated from human meningitis), whose heat resistance was about 11 times lower than that of Lm15 and similar to Lm28 that was about 10 times less heat resistant than Lm15. De Jesús and Whiting (2003) found a narrower distribution from 1.98 to $5.31 \mathrm{~min}$ of the $\mathrm{D}_{60}{ }^{\circ} \mathrm{c}$ values among 21 L. monocytogenes strains isolated from humans and animals, while the range for the same acid-adapted strains was between 0.8 and $4.59 \mathrm{~min}$.

The influence of the matrix on the heat resistance of the selected strain used in the present study was clear and it was probably linked to a combination of protective and inhibiting factors. The high amount of total solids of the drained cheese curd (63.4\%) and of the synthetic TSB medium $(31.5 \mathrm{~g} / \mathrm{L})$ may be related to the high $D$-values measured at all the tested temperatures. No literature data are available about the heat resistance of L. monocytogenes in MBC cheese curds, while $\mathrm{D}_{60^{\circ} \mathrm{c}}$ values in TSB (4.74 min corresponding to $284.4 \mathrm{~s}$ in Table 2) resulted similar to those reported by Quintavalla and Campanini (1991) and Aryani et al. (2015b). A higher thermotolerance of L. monocytogenes in half cream, double cream or butter compared to TSB was reported by Casadei et al. (1998), but no relationship was found between the $D$-values and the fat amount of the product. The presence of undissociated lactic acid in the covering liquid may be responsible for the lowest $D$-values reported in the present study. As the fresh covering liquid contained $0.5 \mathrm{~g}$ of lactic acid/100 $\mathrm{mL}$ at $\mathrm{pH} 2.9$, according to the HendersonHasselbalch equation.

The amount of undissociated acid is near to $90 \%$ corresponding to about $50 \mathrm{mmol} / \mathrm{L}$, largely above the concentration of $6.35 \mathrm{mM}$ indicated by Aryani et al. (2015a) and Wemmenhove et al. (2018) as inhibitory of L. monocytogenes growth. Considering the values obtained in hardening water and brine, the relatively low $\mathrm{NaCl}$ concentration $(4 \mathrm{~g} / 100 \mathrm{~g})$ of the latter fluid did not markedly affect Lm15 heat resistance, probably because the protective effect of salt was counterbalanced by the low $\mathrm{pH}$ value of the brine. The direct relation between salt concentration and L. monocytogenes thermotolerance was observed by several authors (Jørgensen et al., 1995; Juneja et al., 2013; Li et al., 2017).

The calculation of $z$-values between 60 and $70^{\circ} \mathrm{C}$ in the different matrices gave results generally higher (from 8.2 to $11.1^{\circ} \mathrm{C}$ ) than most of the data present in literature, with the exception of $z$-value related to TSB medium $\left(6.4^{\circ} \mathrm{C}\right)$. However, similar or higher $z$-values were found for L. monocytogenes strains tested in some foods such as egg albumen or yolk, meat or flour (Palumbo et al., 1996; Michalski et al., 2000; Taylor et al., 2018). A higher $z$-value means that the strain is more tolerant to the changes in temperatures and this behavior should be taken into account in the design of heat processes.

As the knowledge of $D$ - and $z$-values is pivotal to successfully design food processes, the accuracy of the simulation of the lethal 
TABLE 3 | Estimation of the overall lethal effect of cheese curd stretching on $\operatorname{Lm} 15\left(D_{70^{\circ} \mathrm{C}}=85.36 \mathrm{~s} ; \mathrm{z}=11.1^{\circ} \mathrm{C}\right)$.

\begin{tabular}{|c|c|c|c|c|c|c|}
\hline & Estimated Lm15 D $(\mathrm{s})$ & Temperature $\left({ }^{\circ} \mathrm{C}\right)$ & $\begin{array}{l}\text { Estimated time of } \\
\text { curd residence at } \\
\text { "constant" } \\
\text { temperature (s) }\end{array}$ & $\begin{array}{l}\text { Cumulative } \\
\text { time of } \\
\text { stretching } \\
\text { operation (s) }\end{array}$ & $\begin{array}{c}\log _{10} \text { count } \\
\text { reduction }\end{array}$ & $\begin{array}{l}\log _{10} \text { count } \\
\text { reduction } \\
\text { cumulative }\end{array}$ \\
\hline \multirow[t]{10}{*}{ Curd mixing with hot water } & 681 & 60 & 3 & 3 & 0.00 & 0.00 \\
\hline & 553 & 61 & 4 & 7 & 0.01 & 0.01 \\
\hline & 449 & 62 & 6 & 13 & 0.01 & 0.02 \\
\hline & 365 & 63 & 8 & 21 & 0.02 & 0.05 \\
\hline & 297 & 64 & 10 & 31 & 0.03 & 0.08 \\
\hline & 241 & 65 & 15 & 46 & 0.06 & 0.14 \\
\hline & 196 & 66 & 20 & 66 & 0.10 & 0.24 \\
\hline & 159 & 67 & 25 & 91 & 0.16 & 0.40 \\
\hline & 129 & 68 & 30 & 121 & 0.23 & 0.63 \\
\hline & 105 & 69 & 45 & 166 & 0.43 & 1.06 \\
\hline Kneading of melted curd & 105 & 69 & 200 & 366 & 1.90 & 2.97 \\
\hline Cheese molding & 105 & 69 & 100 & 466 & 0.95 & 3.92 \\
\hline \multirow[t]{9}{*}{ Cheese cooling and hardening } & 129 & 68 & 80 & 546 & 0.62 & 4.54 \\
\hline & 159 & 67 & 80 & 626 & 0.50 & 5.04 \\
\hline & 196 & 66 & 65 & 691 & 0.33 & 5.37 \\
\hline & 241 & 65 & 60 & 751 & 0.25 & 5.62 \\
\hline & 297 & 64 & 50 & 801 & 0.17 & 5.79 \\
\hline & 365 & 63 & 40 & 841 & 0.11 & 5.90 \\
\hline & 449 & 62 & 30 & 871 & 0.07 & 5.97 \\
\hline & 553 & 61 & 30 & 901 & 0.05 & 6.02 \\
\hline & 681 & 60 & 30 & 931 & 0.04 & 6.06 \\
\hline
\end{tabular}

effect due to stretching and other heating operations depends both on the accuracy of the $D$ - and $z$-value estimation, both on the accuracy of the determination of the heat treatment. While temperature changes during fluid heating by flowing through continuous heat exchangers can be predicted by computational fluid dynamics (Rinaldi et al., 2018) or direct measurements, the measurement of the change of temperature of a cheese curd during continuous cooking-stretching operation in industrial conditions, by means of the typical diving arms equipment used in the geographical area, is difficult to be monitored or estimated, and for this reason is lacking in literature. Cheese curd stretching is considered as an asymmetrical heat treatment (Villani et al., 1996; Murru et al., 2018) and just few known examples (Serraino et al., 2013) of description of the temperature evolution are referred to lab scale experiments or to industrial trials performed with batch operations (Mucchetti et al., 1997). The process involves solid/fluid mixing operations, rheological changes due to curd melting, and a flow in a channel with not constant section, responsible for a variable speed and residence time in the different sections of the equipment (tween screw conveyor, diving arms, and molding). The process can be divided in four steps: (i) a first step of fast rise of temperature of the curd mass, which homogeneity depends on the efficacy of cheese curd mixing with hot water into the horizontal counter rotating twin screw conveyor that transports the mixture to the kneading section; (ii) a second step where the melted cheese curd is kneaded by the movement of diving arms and temperature is quite constant and homogenous within the mass; (iii) a third step where the stretched cheese mass enters the molding equipment and it is pulled by a second screw conveyor toward the molding drum; (iv) a final step during which the molded cheese balls fall from the molding drum into flowing tap water where they start to harden and to decrease their temperature; the temperature decrease in the center of the cheese, that is slower than in its external part, is governed by the conductive heat transfer from the center to the surface of the cheese and it is dependent of the cheese ball size. The minimum overall sterilizing effect on L. monocytogenes is the result of the cumulative effect of non-isothermal (the steps of curd mixing with hot water and cheese chilling by dipping in tap water) and quasi-isothermal (the steps of curd kneading and cheese molding, performed without water addition) contributions. The accuracy of lethal effect prediction depends on the correct measurement of the temperature profile of the coldest spot in the non-isothermal steps of the process. This discussion shows the complexity of the phenomenon of heat exchange during the curd stretching operation and the difficulties to foresee the rate of inactivation of microorganisms during cheese curd stretching and cheese hardening. At the same time, beside the strain biodiversity (Murru et al., 2018), the potential process variability can contribute to explain the heterogeneous results obtained by 
challenge tests, where the inactivation of L. monocytogenes ranged from 1 to more than 8 decimal reductions (Villani et al., 1996; Kim et al., 1998; Raimundo et al., 2013; Serraino et al., 2013; Murru et al., 2018). The technological importance of bacterial heterogeneity is also connected to the ability of a small fraction of any population to survive exposure to stresses that kill the majority of the population. The knowledge of heat inactivation kinetics parameters for all the other fluids involved in chilling, salting and storing of MBC cheese is critical to more effectively and efficiently manage the treatment of these fluids to prevent $\mathrm{MBC}$ cheese surface post contamination.

\section{CONCLUSION}

The data supplied in this in vitro study may prove to be useful for MBC and other Mozzarella cheese producers in determining appropriate durations and temperatures for producing fresh pasta filata cheeses avoiding the presence of $L$. monocytogenes. To do so, a further model should be studied to foresee the amount of hot water required to heat the MBC cheese curd mass, considering both the cases of batch or in continuous stretching processes. Finally, the knowledge of the kinetic parameters of heat inactivation together with a deeper knowledge of the temperature vs time evolution of the cheese mass can be a tool to foresee the lethal effect of the process and to better manage the process itself also With the aim to improve the microbial safety of the cheese.

\section{REFERENCES}

Alessandria, V., Rantsiou, K., Dolci, P., and Cocolin, L. (2010). Molecular methods to assess Listeria monocytogenes route of contamination in a dairy processing plant. Int. J. Food Microbiol. 141, S156-S162.

Aryani, D. C., den Besten, H. M. W., Hazeleger, W. C., and Zwietering, M. H. (2015a). Quantifying strain variability in modeling growth of Listeria monocytogenes. Int. J. Food Microbiol. 208, 19-29. doi: 10.1016/j.ijfoodmicro. 2015.05.006

Aryani, D. C., den Besten, H. M. W., Hazeleger, W. C., and Zwietering, M. H. (2015b). Quantifying variability on thermal resistance of Listeria monocytogenes. Int. J. Food Microbiol. 193, 130-138.

Barancelli, G. V., Camargo, T. M., Gagliardi, N. G., Porto, E., Souza, R. A., Campioni, F., et al. (2014). Pulsed-Field Gel Electrophoresis characterization of Listeria monocytogenes isolates from cheese manufacturing plants in São Paulo. Brazil. Int. J. Food Microbiol. 173, 21-29. doi: 10.1016/j.ijfoodmicro.2013.12. 018

Bernini, V., Bottari, B., Dalzini, E., Sgarbi, E., Lazzi, C., Neviani, E., et al. (2013). The presence, genetic diversity and behaviour of Listeria monocytogenes in blue-veined cheese rinds during the shelf life. Food Control 34, 323-330. doi: 10.1016/j.foodcont.2013.04.015

Bigelow, W. D. (1921). The logarithmic nature of thermal death time curves. J. Infect. Dis. 29, 528-536. doi: 10.1093/infdis/29.5.528

Booth, I. R. (2002). Stress and the single cell: intrapopulation diversity is a mechanism to ensure survival upon exposure to stress. Int. J. Food Microbiol. 78, 19-30. doi: 10.1016/s0168-1605(02)00239-8

Bucur, F. I., Grigore-Gurgu, L., Crauwels, P., Riedel, C. U., and Nicolau, A. I. (2018). Resistance of Listeria monocytogenes to stress conditions encountered in food and food processing environments. Front. Microbiol. 9:2700. doi: 10. 3389/fmicb. 2018.02700

\section{DATA AVAILABILITY STATEMENT}

The raw data supporting the conclusions of this article will be made available by the authors, without undue reservation.

\section{AUTHOR CONTRIBUTIONS}

AR: investigation and methodology. MA: methodology and data analysis. FM: investigation and methodology. VB: project administration, supervision, and writing -review and editing. AG: resources. GP: resources. EN: supervision, writing -review and editing. GM: conceptualization, supervision, and writing original draft. All authors contributed to the article and approved the submitted version.

\section{FUNDING}

This work was supported by Consorzio Tutela Mozzarella di Bufala Campana DOP, Caserta, CE, Italy.

\section{ACKNOWLEDGMENTS}

We are grateful to Dr. Matteo Ferrari and Dr. Rossana Volpe for their valuable support.

Budzińska, K., Wroński, G., and Szejniuk, B. (2012). Survival time of bacteria Listeria monocytogenes in water environment and sewage. Pol. J. Environ. Stud. 21, 31-37.

Casadei, M. A., Esteves de Matos, R., Harrison, S. T., and Gaze, J. E. (1998). Heat resistance of Listeria monocytogenes in dairy products as affected by the growth medium. J. Appl. Microbiol. 84, 234-239. doi: 10.1046/j.1365-2672.1998.00334. $\mathrm{x}$

Cebrian, G., Condon, S., and Manas, P. (2017). Physiology of the inactivation of vegetative bacteria by thermal treatments: mode of action, influence of environmental factors and inactivation kinetics. Foods 6:107. doi: 10.3390/ foods6120107

Canadian Food Inspection Agency (CFIA) (2019). Food Recall Warning. Available online at: https://www.inspection.gc.ca/food-recall-warnings-and-allergyalerts/2019-11-28/eng/1574992579686/1574992585649 (accessed March 2, 2020).

Commission Regulation (EC) No. 2073/2005 (2020). Commission Regulation (EC) No 2073/2005 of 15 November 2005 on Microbiological Criteria for Foodstuffs. Official Journal of the European Union 05/12/2005. Available online at: https: //eur-lex.europa.eu/legal-content/EN/ALL/?uri=CELEX\%3A32005R2073 (accessed November 05, 2020).

Davis, K. M., and Isberg, R. R. (2016). Defining heterogeneity within bacterial populations via single cell approaches. Bioessays 38, 782-790. doi: 10.1002/bies. 201500121

De Jesús, A. J., and Whiting, R. C. (2003). Thermal inactivation, growth, and survival studies of Listeria monocytogenes strains belonging to three distinct genotypic lineages. J. Food Prot. 66, 1611-1617.

Doyle, M. E., Mazzotta, A. S., Wang, T., Wiseman, D. W., and Scott, V. N. (2001). Heat resistance of Listeria monocytogenes. J. Food Prot. 64, 410-429.

Gayan, E., Serrano, M. J., Pagan, R., Alverez, I., and Condon, A. S. (2015). Environmental and biological factors influencing the UV-C resistance of Listeria monocytogenes. Food Microbiol. 46, 246-253. doi: 10.1016/j.fm.2014. 08.011 
Geeraerd, A. H., Valdramidis, V., and Van Impe, J. F. (2005). GInaFiT, a freeware tool to assess non-log-linear microbial survivor curves. Int. J. Food Microbiol. 102, 95-105. doi: 10.1016/j.ijfoodmicro.2004.11.038

Gião, M. S., and Keevil, C. W. (2014). Listeria monocytogenes can form biofilms in tap water and enter into the viable but non-cultivable state. Microb. Ecol. 67, 603-611. doi: 10.1007/s00248-013-0364-3

Jørgensen, F., Hansen, T. B., and Knøchel, S. (1999). Heat shock-induced thermotolerance in Listeria monocytogenes 13-249 is dependent on growth phase, pH and lactic acid. Food Microbiol. 16, 185-194. doi: 10.1006/fmic.1998. 0222

Jørgensen, F., Stephens, P. J., and Knøchel, S. (1995). The effect of osmotic shock and subsequent adaptation on the thermotolerance and cell morphology of Listeria monocytogenes. J. Appl. Bacteriol. 79, 274-281. doi: 10.1111/j.13652672.1995.tb03137.x

Juneja, V. K., Altuntaş, E. G., Ayhan, K., An Hwang, C., Sheen, S., and Friedman, M. (2013). Predictive model for the reduction of heat resistance of Listeria monocytogenes in ground beef by the combined effect of sodium chloride and apple polyphenols. Int. J. Food Microbiol. 164, 54-59. doi: 10.1016/j. ijfoodmicro.2013.03.008

Kim, J., Schmidt, K. A., Phebus, R. K., and Jeon, I. J. (1998). Time and temperature of stretching as critical control points for Listeria monocytogenes during production of mozzarella cheese. J. Food Prot. 61, 116-118. doi: 10.4315/0362028x-61.1.116

Li, C., Huang, L., and An Hwang, C. (2017). Effect of temperature and salt on thermal inactivation of Listeria monocytogenes in salmon roe. Food Control 73, 406-410. doi: 10.1016/j.foodcont.2016.08.027

Lou, Y., and Yousef, A. E. (1996). Resistance of Listeria monocytogenes to heat after adaptation to environmental stresses. J. Food Prot. 59, 465-471.

Lyautey, E., Lapen, D. R., Wilkes, G., McCleary, K., Pagotto, F., Tyler, K., et al. (2007). Distribution and characteristics of Listeria monocytogenes isolates from surface waters of the south nation river watershed, Ontario, Canada. Appl. Environ. Microbiol. 73, 5401-5410. doi: 10.1128/aem.00354-07

Mafart, P., Couvert, O., Gaillard, S., and Leguerinel, I. (2002). On calculating sterility in thermal preservation methods: application of the Weibull frequency distribution model. Int. J. Food Microbiol. 72, 107-113. doi: 10.17660/ actahortic.2001.566.11

Mazzotta, A. S. (2001). Thermal inactivation of stationary-phase and acid-adapted Escherichia coli O157:H7, Salmonella, and Listeria monocytogenes in fruit juices. J. Food Prot. 64, 315-320. doi: 10.4315/0362-028x-64.3.315

Michalski, C. B., Brackett, R. E., Jung, Y. C., and Ezeike, G. O. I. (2000). Use of capillary tubes and plate heat exchanger to validate USDA pasteurization protocols for elimination of Listeria monocytogenes in liquid egg products. J. Food Prot. 63, 921-925. doi: 10.4315/0362-028x-63.7.921

Mucchetti, G., Carminati, D., and Addeo, F. (1997). "Tradition and innovation in the manufacture of the water buffalo Mozzarella cheese produced in Campania," in Proceedings of the 5th World Buffalo Congress 13-16 October 1997, Caserta, 173-181.

Mucchetti, G., and Neviani, E. (2006). Microbiologia e Tecnologia Lattiero Casearia. Qualità e Sicurezza. Milan: Tecniche Nuove Editore, 1-880.

Mucchetti, G., Pugliese, A., and Paciulli, M. (2016). "Characteristics of some important italian cheeses," in Mediterranean Foods Composition and Processing, eds R. M. S. Cruz and M. C. Vieira (Boca Raton, FL: CRC Press- Taylor \& Francis Group), 1-34. doi: 10.1201/9781315369235-1

Murru, N., Peruzy, M. F., Carlo, E., Mercogliano, R., Aponte, M., Morena, C., et al. (2018). Listeria monocytogenes survival during production and storage of water buffalo Mozzarella cheese. Int. J. Dairy Technol. 71, 356-361. doi: 10.1111/1471-0307.12449
Palumbo, M. S., Beers, S. M., Bhaduri, S., and Palumbo, S. A. (1996). Thermal resistance of Listeria monocytogenes and Salmonella spp. in liquid egg white. J. Food Prot. 59, 1182-1186. doi: 10.4315/0362-028x-59.11.1182

Peleg, M., and Cole, M. B. (1998). Reinterpretation of microbial survival curves. Crit. Rev. Food Sci. Nutr. 38, 353-380. doi: 10.1080/10408699891274246

Quintavalla, S., and Campanini, M. (1991). Effect of rising temperature on the heat resistance of Listeria monocytogenes in meat emulsion. Lett. Appl. Microbiol. 12, 184-187. doi: 10.1111/j.1472-765x.1991.tb00535.x

Raimundo, D. C., Travaglini, R. G., Souza, G. O., Starikoff, K. R., Sanches, S. A., Souza, O. B., et al. (2013). Methods for thermal inactivation of pathogens in mozzarella: a comparison between stretching and pasteurization. Arq. Bras. Med. Vet. Zootec. 65, 582-588. doi: 10.1590/s0102-09352013000200039

RASFF Portal (2020). Available online at: https://webgate.ec.europa.eu/rasffwindow/portal/?event=searchResultList\&StartRow=201 (accessed March 2, 2020).

Rinaldi, M., Cordioli, M., Alinovi, M., Malavasi, M., Barbanti, D., and Mucchetti, G. (2018). Development and validation of CFD models of thermal treatment on milk whey proteins dispersion in batch and continuous process condition. Int. J. Food Eng. 14, 9-10. doi: 10.1515/ijfe-2018-0142

Ryall, B., Eydallin, G., and Ferenci, T. (2012). Culture history and population heterogeneity as determinants of bacterial adaptation: the adaptomics of a single environmental transition. Microbiol. Mol. Biol. Rev. 76, 597-625. doi: 10.1128/mmbr.05028-11

Schirmer, B. C. T., Heir, E., Lindstedt, B. A., Møretrø, T., and Langsrud, S. (2014). Use of used vs. fresh cheese brines and the effect of $\mathrm{pH}$ and salt concentration on the survival of Listeria monocytogenes. J. Dairy Res. 81, 113-119. doi: $10.1017 /$ s0022029913000666

Serraino, A., Finazzi, G., Marchetti, G., Daminelli, P., Riu, R., Giacometti, F., et al. (2013). Fate of Listeria monocytogenes during production and storage of artisan water buffalo mozzarella cheese. Ital. J. Food Sci. 25, 16-22.

Somolinos, M., Espina, L., Pagan, R., and Garcia, D. (2010). sigB absence decreased Listeria monocytogenes EGD-e heat resistance but not its pulsed electric fields resistance. Int. J. Food Microbiol. 141, 32-38. doi: 10.1016/j.ijfoodmicro.2010. 04.023

Taylor, M. H., Tsai, H. C., Rasco, B., Tang, J., and Zhu, M. J. (2018). Stability of Listeria monocytogenes in wheat flour during extended storage and isothermal treatment. Food Control 91, 434-439. doi: 10.1016/j.foodcont.2018.04.008

Villani, F., Pepe, O., Mauriello, G., Moschetti, G., Sannino, L., and Coppola, S. (1996). Behaviour of Listeria monocytogenes during the traditional manufacture of water-buffalo Mozzarella cheese. Lett. Appl. Microbiol. 22, 357-360. doi: 10.1111/j.1472-765x.1996.tb01178.x

Wemmenhove, E., van Valenberg, H. J. F., van Hooijdonk, A. C. M., Wells-Bennik, M. H. J., and Zwietering, M. H. (2018). Factors that inhibit growth of Listeria monocytogenes in nature ripened Gouda cheese: a major role for undissociated lactic acid. Food Control 84, 413-418. doi: 10.1016/j.foodcont.2017.08.028

Conflict of Interest: The authors declare that the research was conducted in the absence of any commercial or financial relationships that could be construed as a potential conflict of interest.

Copyright (C) 2021 Ricci, Alinovi, Martelli, Bernini, Garofalo, Perna, Neviani and Mucchetti. This is an open-access article distributed under the terms of the Creative Commons Attribution License (CC BY). The use, distribution or reproduction in other forums is permitted, provided the original author(s) and the copyright owner(s) are credited and that the original publication in this journal is cited, in accordance with accepted academic practice. No use, distribution or reproduction is permitted which does not comply with these terms. 